\title{
Radiossensibilidade de dois tipos de propágulos de citros
}

\author{
Daniela Loschtschagina Gonzaga ( $\left.{ }^{1}\right)$; Rodrigo Rocha Latado $\left({ }^{1 *}\right)$; Augusto Tulmann Neto $\left({ }^{2}\right)$; \\ Rose Mary Pio (')
}

(') Centro Avançado de Pesquisa Tecnológica do Agronegócio de Citros Sylvio Moreira, Instituto Agronômico de Campinas, Caixa Postal 4, 13490-970 Cordeirópolis (SP). E-mail: rodrigo@centrodecitricultura.br ( ${ }^{*}$ ) Autor correspondente. (2) Centro de Energia Nuclear na Agricultura, Universidade de São Paulo, Av. Centenário, 303, 13416-000 Piracicaba, (SP).

Recebido: 25/mai./2009; Aceito: 8/jan./2010

\section{Resumo}

Em programas de melhoramento de citros por indução de mutações já foi comprovada a sensibilidade diferencial às doses de mutagênico em plantas de diferentes variedades e em diferentes propágulos de uma mesma planta. O objetivo do presente estudo foi avaliar a radiossensibilidade de dois tipos de propágulos (borbulhas e segmentos de epicótilo in vitro) de tangor 'Murcott', tangerinas 'Thomas' e 'Fremont' e limão 'Cravo' (este apenas de segmentos de epicótilo in vitro) e comparar a radiossensibilidade entre propágulos e entre variedades. Foram utilizadas as doses de 0, 10, 20, 30, 40 e 50 Gy de raios-gama, com avaliações aos 60 dias dos parâmetros: porcentagem de borbulhas mortas, altura das brotações desenvolvidas, para borbulhas irradiadas; número de brotações regeneradas por explante e porcentagem de explantes responsivos, para segmentos de epicótilo in vitro irradiados. As diversas doses de radiação testadas em borbulhas causaram reduções significativas no parâmetro altura das brotações desenvolvidas das três variedades. No experimento de irradiação de segmentos de epicótilo in vitro apenas o tangor 'Murcott' e o limão 'Cravo' tiveram reduções significativas no número de brotações regeneradas por explante, em função do aumento da dose de mutagênico. Neste trabalho foi possível determinar que a radiossensibilidade de propágulos in vitro (segmentos de epicótilo) e in vivo (borbulhas) era variável em função da variedade; no caso de tangerina 'Fremont', os segmentos de epicótilo in vitro foram mais sensíveis e, em outros casos, a sensibilidade foi semelhante.

Palavras-chave: radiação, sensibilidade, raios gama, Citros.

\section{Radiossensitivity of two propagules of citrus}

\section{Abstract}

Studies have shown that the radiossensitivity in plants varies depending on the varieties and the propagules used in mutagenic treatment. The purpose of this study was to evaluate the radiossensitivity of two types of propagules (buds and in vitro segments of epicotyl) in 'Murcott' tangor, 'Thomas' and 'Fremont' mandarins and 'Rangpur' lime (only in vitro segments of epicotyl) and to compare the gamma-rays sensitivity among propagules and among varieties. The following doses were used: 0 , 10, 20, 30, 40 and 50 Gy of gamma-rays. The parameters shoot mortality and shoot height, for experiment of bud irradiation, and number of regenerated shoots per explant and percentage of responsive explants, for experiment of peicotyl segments irradiation were evaluated after 60 days. The mutagenic doses tested in buds caused significant reduction in shoot height of all varieties. In the experiment of irradiation of in vitro segments of epicotyl, only 'Murcott' tangor and 'Rangpur' lime showed significant reduction in the number of regenerated shoots per explant, due to the increase of mutagen doses. Results indicate that radiossensitivity of in vitro (segments of epicotyl) and in vivo (buds) propagules is variable depending on the variety. Also, in some cases the in vitro propagules are more sensitive, to irradiation and in other cases, there is no differential sensibility.

Key words: radiation, sensitivity, gamma-rays, Citrus. 
Os primeiros programas de melhoramento tradicionais de citros foram realizados no Estado da Flórida (EUA), por Swingle e Webber, a partir de 1893 (Davies e Albrigo, 1994). Desde entáo, os maiores avanços foram obtidos a partir de cruzamentos interespecíficos visando à obtenção de novas variedades de porta-enxerto e copa, já tendo sido lançadas algumas variedades comerciais de citrumelos (Poncirus trifoliata Raf. $x$ Citrus paradisi Macfad.), citranges [P. trifoliata $\times C$. sinensis sinensis (L.) Osbeck], citrandarins (P. trifoliata $\times$ C. reticulata Blanco) (PoMPeU JUNIOR, 2005) e tangores [C. sinensis sinensis (L.) Osbeck x C. reticulata Blanco].

Já os híbridos intraespecíficos de espécies cítricas para uso como variedades de copa (limóes e laranjas doces, por exemplo) alcançaram menores resultados devido às barreiras reprodutivas das espécies (poliembrionia, ciclo juvenil longo e alta heterozigosidade), o que dificulta a realizaçáo dos cruzamentos e, também, pela dificuldade de se obter progênies contendo plantas com frutos característicos da espécie, como foi citado por Malik et al. (1974) a respeito dos cruzamentos envolvendo limóes [C. limon (L.) Burm. f.].

Apesar da importância das mutaçóes espontâneas na obtenção de novas variedades de citros, a frequência de aparecimento destas mutaçóes é baixa e pode ser aumentada por meio do uso de mutagênese induzida. Por este motivo, a mutagênese induzida tem sido rotineiramente utilizada em programas de melhoramento de citros em vários países (Tulmann Neto et al., 1990; Hearn, 1984; Spiegel-Roy et al., 1990; Shanchun et al., 1991).

Uma questáo importante é a existência de variação na sensibilidade à dose de mutagênico utilizada, entre plantas de diferentes variedades ou entre plantas de diferentes espécies, assim como entre diferentes propágulos de uma mesma planta (sementes, borbulhas, ápice caulinar, explantes in vitro, etc.). Antes de induzir mutaçôes em plantas há a necessidade de se realizar testes de radiossensibilidade para determinar a dose mais apropriada, buscando sempre maximizar as chances de obter mutantes com valor econômico (Tulmann Neto et al., 1990).

Os testes de radiossensibilidade geralmente são planejados para se avaliar os efeitos fisiológicos de diferentes doses de radiação na taxa de crescimento (GR-Growth reduction) ou na letalidade de plantas (LD- Letal dose). Como a frequência de ocorrência de efeitos fisiológicos geralmente possui alta correlação com a frequência de aparecimento de mutações é possível escolher uma dose intermediária para uso em grande quantidade de propágulos, dose esta que possibilita a ocorrência de mutaçôes sem, contudo, causar elevados danos fisiológicos (Tulmann Neto et al., 1998).

O objetivo do presente estudo foi avaliar a radiossensibilidade de propágulos de diversas variedades de citros (limão 'Cravo', tangor 'Murcott' e tangerinas 'Thomas' e 'Fremont') visando determinar a dose adequada para uso no programa de melhoramento por indução de mutaçóes, assim como comparar a radiossensibilidade entre dois tipos de propágulos (borbulhas e segmentos de epicótilo in vitro) de cada variedade e entre o mesmo propágulo, em diferentes variedades.

A radiossensibilidade de borbulhas foi avaliada nas variedades tangor 'Murcott', tangerinas 'Thomas' $\mathrm{e}$ 'Fremont'. Para tal, estacas contendo borbulhas foram destacadas de plantas matrizes mantidas no Centro de Análise e Pesquisa Tecnológica do Agronegócio de Citros Sylvio Moreira- IAC e, a seguir, foram irradiadas com doses de 10, 20, 30, 40 e 50 Gy de raios-gama na fonte de Cobalto 60 do CENA-USP (Piracicaba, SP). A taxa de dose utilizada foi de, aproximadamente, $800 \mathrm{~Gy}$ $\mathrm{h}^{-1}$. Estacas não irradiadas foram usadas como controle experimental.

Após a irradiação, as borbulhas foram destacadas e enxertadas sobre plantas de limão 'Cravo', sendo utilizadas 40 borbulhas por tratamento em delineamento inteiramente casualizado. Após 60 dias da enxertia, foram feitas avaliaçôes dos seguintes parâmetros: porcentagem de borbulhas mortas e a altura das brotaçôes desenvolvidas, denominadas $\mathrm{M}_{1} \mathrm{~V}_{1}$. Os dados de porcentagem de borbulhas mortas em cada dose de mutagênico foram calculados como a razão entre o número de borbulhas mortas e o número total de borbulhas enxertadas.

A análise estatística dos dados foi feita apenas para o parâmetro altura das brotaçóes desenvolvidas, em cada variedade separadamente, com uso do teste $\mathrm{F}$ e teste de Tukey a 5\%, para comparar as médias dos tratamentos. A seguir, foram realizadas análises de regressáo linear dos dados médios obtidos de cada dose e para cada variedade, além da análise de paralelismo e coincidência de retas utilizando-se o programa ESTAT versão 2.0 , para verificar a existência de diferenças significativas entre as retas.

A radiossensibilidade de segmentos de epicótilo in vitro foi avaliada em tangor 'Murcott', tangerinas 'Thomas' e 'Fremont' e o limão 'Cravo'. Os segmentos de epicótilo foram obtidos a partir de sementes germinadas in vitro, desinfectadas previamente em soluçấo de hipoclorito de sódio (água sanitária pura) por cerca de 10 minutos e lavadas três vezes em água destilada autoclavada. As sementes foram inoculadas em tubos de ensaio contendo meio de cultura semi-sólido composto apenas por sais de MS na metade da concentração e solidificados com ágar $(0,7 \%)$. $\mathrm{O}$ pH do meio foi ajustado para 5,8 antes da esterilização por autoclavagem. Os tubos foram mantidos no escuro a $25 \pm 1{ }^{\circ} \mathrm{C}$ durante 30 dias, até a germinação das sementes e obtenção de plântulas estioladas.

Segmentos de epicótilo com cerca de $0,5 \mathrm{~cm}$ de comprimento foram extraídos das plântulas germinadas in vitro com uso de pinça e estilete e, a seguir, foram irradiados com doses de $0,10,20,30,40$ e 50 Gy de raiosgama (com taxa de dose média de $800 \mathrm{~Gy} \mathrm{~h}^{-1}$ ) na fonte 
GammaCell do CENA/USP. Um total de 40 segmentos de epicótilo foi usado por tratamento.

Os explantes foram cultivados em placas de Petri contendo meio de cultura semissólido composto por sais e vitaminas de MT, 50,0 $\mathrm{g} \mathrm{L}^{-1}$ de sacarose, $0,5 \mathrm{~g} \mathrm{~L}^{-1} \mathrm{de}$ extrato de malte, $0,7 \%$ de ágar e suplementado com 2,0 $\mathrm{mg} \mathrm{L}^{-1}$ BAP, para indução da organogênese somática. O $\mathrm{pH}$ do meio foi ajustado para 5,8 antes da esterilização por autoclavagem.

As placas foram mantidas durante duas semanas no escuro, a $25 \pm 1{ }^{\circ} \mathrm{C}$ e após, transferidas para condiçóes de 16 horas de luz ( $49 \mu \mathrm{mol} \cdot \mathrm{m}^{-2} \cdot \mathrm{s}^{-1}$ de intensidade luminosa) e a $25 \pm 1^{\circ} \mathrm{C}$, por até 60 dias.

$\mathrm{O}$ efeito das diversas doses de mutagênico nos segmentos de epicótilo foi avaliado no fim do experimento, com a contagem do número de brotaçốes regeneradas por explante e a porcentagem de explantes responsivos, isto é, que regeneravam ao menos em uma brotação. Este último parâmetro foi calculado como a razão entre o número de explantes responsivos e o número total de explantes inoculados.

O delineamento experimental foi o inteiramente casualizado e os dados do parâmetro número de brotaçôes regeneradas por explante foram transformados por raiz de $\mathrm{x}+0,5$ antes da realização das análises estatísticas, as mesmas citadas anteriormente.

Em seguida, os efeitos das diversas doses de radiação gama nos dois propágulos foram comparados em tangor 'Murcott', tangerinas 'Fremont' e 'Thomas' separadamente, utilizando-se as análises estatísticas de coincidência e de paralelismo de retas.

No experimento de irradiação de borbulhas, os dados de altura das brotações desenvolvidas demonstraram que apenas algumas doses de radiação causaram reduçóes significativas neste parâmetro, nas três variedades de citros (Tabela 1).

Já para o parâmetro porcentagem de borbulhas mortas, o aumento consistente em função do aumento da dose de mutagênico ocorreu apenas para o tangor 'Murcott' e resultados inconsistentes foram observados nas demais variedades (Tabela 1). Uma possível explicação para tal fato é que o tempo para a avaliação da sobrevivência pode ter sido relativamente curto (60 dias). Deste modo, nas doses mais elevadas de mutagênico pode ter ocorrido o fato de muitas borbulhas que não tinham desenvolvimento (mas foram consideradas como vivas) aos 60 dias da irradiaçáo, poderiam passar a ser consideradas como mortas após um maior período de tempo. Apesar disto, é possível observar que houve alta porcentagem de mortalidade nas três variedades quando utilizada a dose mais elevada (50 Gy).

Gulsen et al. (2007) tambêm observaram haver reduções crescentes e contínuas na altura das brotaçôes e na porcentagem de borbulhas sobreviventes em função do aumento das doses de raios-gama, em um trabalho de indução de mutaçōes em limão 'Kutdiken'.

Pelos testes de paralelismo e coincidência de retas dos dados de regressão linear de altura das brotaçóes desenvolvidas observou-se que as três variedades avaliadas (tangor 'Murcott', tangerinas 'Thomas' e 'Fremont') tiveram retas coincidentes e paralelas entre si, pois os testes F para coincidência de retas e t para paralelismo de retas foram sempre não significativos ('Murcott' $\mathrm{x}$ 'Fremont' - $F=4,3 n s, t=1,4 n s$ e 'Murcott' $x$ 'Thomas' - $F=3,6$ ns e $\mathrm{t}=0,2 \mathrm{~ns}$ e 'Thomas' e 'Fremont' - $\mathrm{F}=1,7 \mathrm{~ns}$ e $\mathrm{t}=1,6 \mathrm{~ns}$ ).

Com base nas equaçôes de retas obtidas para cada variedade foi possível selecionar as doses GR 30 e GR 50 (doses que causaram a redução de $30 \%$ e $50 \%$ na altura das brotaçôes desenvolvidas respectivamente). Para a tangerina 'Thomas' as doses de mutagênico determinadas como GR 30 e GR 50 foram de 19,9 e 33,2 Gy de raios-gama, enquanto para a tangerina 'Fremont', as doses foram de 33,5 e 55,8 Gy e para o tangor 'Murcott', doses de 16,3 e 27,2 Gy de raios-gama.

Spiegel-Roy e Padova (1973) e Spiegel-Roy e Коснва (1975) relatam que o LD 50 para borbulhas

Tabela 1. Altura das brotações desenvolvidas (dados observados e ajustados pelas respectivas equaçóes de regressão linear) e porcentagem de borbulhas mortas, com avaliação 60 dias após o tratamento mutagênico com diversas doses de raios-gama

\begin{tabular}{|c|c|c|c|c|c|c|c|c|c|}
\hline \multirow{3}{*}{$\begin{array}{l}\text { Dose } \\
\text { Gy }\end{array}$} & \multicolumn{2}{|c|}{ Fremont } & \multirow[b]{3}{*}{$\%$} & \multicolumn{2}{|c|}{ Thomas } & \multicolumn{4}{|c|}{ Murcott } \\
\hline & \multicolumn{2}{|c|}{ Obs.( $\left.{ }^{1}\right) \quad$ Ajust. $\left({ }^{2}\right)$} & & \multicolumn{2}{|c|}{ Obs.(1) Ajust.( ${ }^{(2)}$} & \multicolumn{4}{|c|}{ Obs.(1) Ajust. $\left({ }^{2}\right)$} \\
\hline & $\mathrm{cm}$ & cm & & $\mathrm{cm}$ & $\mathrm{cm}$ & $\%$ & cm & $\mathrm{cm}$ & $\%$ \\
\hline 0 & $14,8 \mathrm{a}$ & 16,4 & 2 & $17,6 \mathrm{a}$ & 18,3 & 7 & $13,6 a b$ & 15,6 & 31 \\
\hline 10 & $13,3 \mathrm{a}$ & 14,9 & 12 & $15,9 \mathrm{a}$ & 15,6 & 2 & $15,9 \mathrm{a}$ & 12,8 & 45 \\
\hline 20 & $15,6 \mathrm{a}$ & 13,4 & 0 & $12,5 b$ & 12,8 & 7 & $10,7 \mathrm{~b}$ & 9,9 & 36 \\
\hline 30 & $14,6 \mathrm{a}$ & 12,0 & 5 & $11,2 b$ & 10,1 & 2 & $5,7 \mathrm{c}$ & 7,0 & 55 \\
\hline 40 & $13,2 \mathrm{a}$ & 10,5 & 2 & $8,2 \mathrm{~b}$ & 7,3 & 7 & $1,8 \mathrm{c}$ & 4,1 & 79 \\
\hline 50 & $4,8 b$ & 9,0 & 38 & $3,2 \mathrm{c}$ & 4,5 & 50 & $3,0 \mathrm{c}$ & 1,3 & 95 \\
\hline Teste $F\left({ }^{3}\right)$ & $11,1^{* *}$ & & & 35,4 ** & & & $12,9^{* *}$ & & \\
\hline CV (\%) & 48,0 & & & 39,6 & & & 53,8 & & \\
\hline
\end{tabular}

(1) Valores observados, médias seguidas da mesma letra na coluna nâo apresentam diferenças significativas pelo teste de Tukey a 0,05 de probabilidade. $\left({ }^{2}\right)$ Valores ajustados pelas respectivas equaçóes de regressão linear dos dados: Fremont $y=-0,15 x+16,4\left(R^{2}=0,71\right)$; Thomas $y=-0,28 x+18,3\left(R^{2}=0,97\right)$ e Murcott $y=-0,29 x+15,6\left(R^{2}=0,85\right)$. $\left({ }^{3}\right) * *$ significativo ao nível de 0,01 de probabilidade pelo teste $\mathrm{F}$. 
de laranjas doces se situava na faixa entre 40 e 80 Gy e para a irradiaçáo de embriôes nucelares em sementes, a dose seria de aproximadamente 100 Gy. Já Gulsen et al. (2007) definiram que o LD 50 para limão 'Kutdiken' era aproximadamente 50 Gy de raios-gama, próximo do resultado obtido para o GR 50 com a variedade 'Fremont' no presente estudo.

No experimento de avaliação da radiossensibilidade de segmentos de epicótilo in vitro os resultados foram divergentes para o tangor 'Murcott' e o limão 'Cravo', que apresentaram reduçōes significativas no número de brotaçôes regeneradas por explante e tendência à redução na porcentagem de epicótilos responsivos, em função do aumento da dose de mutagênico. Já as duas variedades de tangerina estudadas ('Fremont' e 'Thomas') não apresentaram este padrão mesmo na dose mais elevada de mutagênico (50 Gy de raios-gama), não se podendo observar diferenças significativas entre tratamentos para os dois parâmetros: número de brotaçôes regeneradas por explante e porcentagem de explantes responsivos (Tabela 2).

Utilizando-se as respectivas equações de regressôes lineares de cada variedade foi possível calcular para cada variedade as doses de mutagênico que correspondiam ao GR 30 e GR 50 para os segmentos de epicótilo in vitro, que seriam respectivamente 18,0 e 30,0 Gy para a tangerina 'Thomas', 13,5 e 22,4 Gy para a 'Fremont', 16,2 e 27,0 Gy para o tangor 'Murcott' e 20,7 e 34,5 Gy para o Limão 'Cravo'.

As doses de mutagênico mais comumente utilizadas para propágulos in vitro de citros variam muito principalmente em funçáo do explante utilizado. Como exemplos podem ser citados o uso de 4,5 a 7,5 Gy de raios-gama para irradiação de protoplastos de laranja doce (SPIEGEL-Roy, 1979), 20-40 Gy para uso em plântulas in vitro decapitadas (Spiegel-Roy e Kochba, 1973) e 120-160 Gy, para irradiação de calos originados de óvulos não fertilizados (Кochba e Spiegel-Roy, 1976, 1977).
Nos dados obtidos com a irradiaçáo de segmentos de epicótilo, os testes de coincidência entre retas indicaram que as quatro variedades tiveram equaçóes de reta não coincidentes (testes $\mathrm{F}$ significativos para coincidência de retas). Já os testes de paralelismo entre retas indicaram que, à exceção da comparação entre tangerina 'Fremont' e tangor 'Murcott', todas as outras comparaçóes possíveis entre duas variedades resultaram em retas consideradas como paralelas entre si (testes $t$ náo significativos para paralelismo de retas) demonstrando que as variedades possuíam retas com mesma inclinação.

Em tangerina 'Fremont' e tangor 'Murcott' com equações de reta não coincidentes $\left(\mathrm{F}=24,3^{*}\right)$ e não paralelas $\left(\mathrm{t}=3,1^{*}\right)$ entre $\mathrm{si}$, observou-se que não possuíam o mesmo padrão de resposta em função do aumento das doses de mutagênico. Já o limão Cravo, apesar de ter reta paralela em relação às demais, destacou-se pela maior taxa de regeneraçáo de brotaçóes in vitro, inclusive no controle (explantes não irradiados) (Tabela 2).

As análises comparativas da radiossensibilidade de borbulhas e de segmentos de epicótilo in vitro dentro de uma mesma variedade demonstraram que, para todas, houve diferenças estatisticamente significativas entre as equaçôes de regressão linear. Esse fato pode ser detectado pelos testes $\mathrm{F}$ para coincidência e teste t para paralelismo entre retas, com resultados significativos (tangerina 'Fremont'- $\mathrm{F}=47,5^{* *}$ e $\mathrm{t}=-3,0^{*}$; tangerina 'Thomas'- $\mathrm{F}=377,2^{* *}$ e $\mathrm{t}=-10,4^{* *}$ e tangor 'Murcott'$\mathrm{F}=42,6^{* *}$ e $\left.\mathrm{t}=-4,6^{* *}\right)$.

Os segmentos de epicótilo in vitro de tangerina 'Fremont' tiveram maior sensibilidade ao mutagênico do que os propágulos in vivo (borbulhas) pois a inclinação da reta observada para o propágulo in vitro era maior (Figura 1a); pode-se concluir que, para uma mesma dose de mutagênico, a reduçáo do desenvolvimento seria maior para o propágulo in vitro. De fato, a dose GR 30 calculada, para os propágulos in vitro desta variedade, foi de 13,5 Gy de raios-gama, menor do que o calculado para as borbulhas, 33,5 Gy.

Tabela 2. Número de brotaçôes regeneradas por explante (dados observados e ajustados pelas respectivas equações de regressão linear) e porcentagem de explantes responsivos, com avaliação 60 dias após o tratamento mutagênico de segmentos de epicótilo in vitro com diversas doses de raios-gama

\begin{tabular}{|c|c|c|c|c|c|c|c|c|c|c|c|c|}
\hline \multirow{4}{*}{$\begin{array}{l}\text { Dose } \\
\text { Gy } \\
0\end{array}$} & \multicolumn{2}{|c|}{ Fremont } & \multicolumn{4}{|c|}{ Thomas } & \multicolumn{2}{|c|}{ Murcott } & \multicolumn{4}{|c|}{ Limão Cravo } \\
\hline & \multicolumn{2}{|c|}{ Ob.(') Aj. $\left(^{(2)}\right.$} & \multirow{3}{*}{$\begin{array}{c}\% \\
10,6\end{array}$} & \multicolumn{2}{|c|}{ Ob. $\left({ }^{1}\right) \quad$ Aj. $\left({ }^{2}\right)$} & \multirow{3}{*}{$\begin{array}{c}\% \\
22,2\end{array}$} & \multirow{2}{*}{\multicolumn{2}{|c|}{$\begin{array}{c}\text { Ob. }\left({ }^{1}\right) \text { Aj. }\left({ }^{2}\right) \\
\text { N. }\end{array}$}} & \multicolumn{4}{|c|}{ Ob. ( $\left.{ }^{1}\right) \quad$ Aj..$\left(^{2}\right)$} \\
\hline & \multicolumn{2}{|c|}{ N. ${ }^{\circ}$} & & \multicolumn{2}{|c|}{ N. ${ }^{\circ}$} & & & & $\%$ & \multicolumn{2}{|c|}{ N. ${ }^{\circ}$} & $\%$ \\
\hline & 0,24 & 0,2 & & $0,40 \mathrm{a}$ & 0,3 & & $0,60 \mathrm{a}$ & 0,6 & 33,3 & $0,89 a$ & 1,2 & 52,9 \\
\hline 10 & 0,11 & 0,1 & 8,6 & $0,26 a$ & 0,3 & 15,2 & $0,45 a b$ & 0,5 & 27,3 & $1,16 \mathrm{a}$ & 1,0 & 63,3 \\
\hline 20 & 0,03 & 0,1 & 3,0 & $0,11 \mathrm{a}$ & 0,2 & 8,5 & $0,42 a b$ & 0,4 & 15,2 & $1,14 \mathrm{a}$ & 0,8 & 53,5 \\
\hline 30 & 0,06 & 0,1 & 6,1 & $0,28 a$ & 0,2 & 15,2 & $0,15 a b$ & 0,3 & 5,9 & $0,56 b$ & 0,7 & 21,8 \\
\hline 40 & 0,00 & 0,0 & 0,0 & $0,13 \mathrm{a}$ & 0,1 & 6,4 & $0,23 a b$ & 0,2 & 12,9 & $0,48 b$ & 0,5 & 17,0 \\
\hline 50 & 0,03 & 0,0 & 3,0 & $0,04 \mathrm{a}$ & 0,1 & 2,2 & $0,03 \mathrm{~b}$ & 0,0 & 3,0 & $0,23 b$ & 0,3 & 8,6 \\
\hline Teste $\mathrm{F}^{(3)}$ & $1,6 \mathrm{~ns}$ & & & $2,3 *$ & & & $2,7^{*}$ & & & 17,3 ** & & \\
\hline C.V. (\%) & 22,5 & & & 32,9 & & & 38,1 & & & 42,8 & & \\
\hline
\end{tabular}

(1) Valores observados, médias seguidas da mesma letra na coluna não apresentam diferenças significativas pelo teste de Tukey a 0,05 de probabilidade. $\left({ }^{2}\right)$ Valores ajustados pelas respectivas equaçóes de regressáo linear dos dados: Fremont $y=-0,004 x+0,17\left(R^{2}=0,68\right)$; Thomas $y=-0,006 x+0,35\left(R^{2}=0,66\right)$; Murcott $y=-0,01 x+0,58\left(R^{2}=0,90\right)$ e Limão Cravo y =-0,02x $+1,17\left(\mathrm{R}^{2}=0,70\right) .\left({ }^{3}\right)^{*} \mathrm{e}^{* *}$ significativos ao nível de 0,05 e 0,01 de probabilidade respectivamente, pelo teste $\mathrm{F}$. ns= nấo significativo. 
Para a variedade 'Thomas' foi possível notar que as diferenças, apesar de significativas, foram bem menores entre as equaçôes de regressão linear dos segmentos de epicótilo in vitro e das borbulhas (in vivo). Na figura $1 \mathrm{~b}$, pode-se observar que os dois tipos de propágulos têm respostas muito próximas em função das diversas doses de mutagênico, o que pode ser demonstrado pelas doses de GR 30 calculadas, que foram de 18,0 e 19,9 Gy para os propágulos in vitro e in vivo respectivamente. $\mathrm{O}$ mesmo pôde ser observado para o tangor 'Murcott' cujas doses de GR 30 calculadas foram de 16,2 e 16,3 Gy de raios-gama
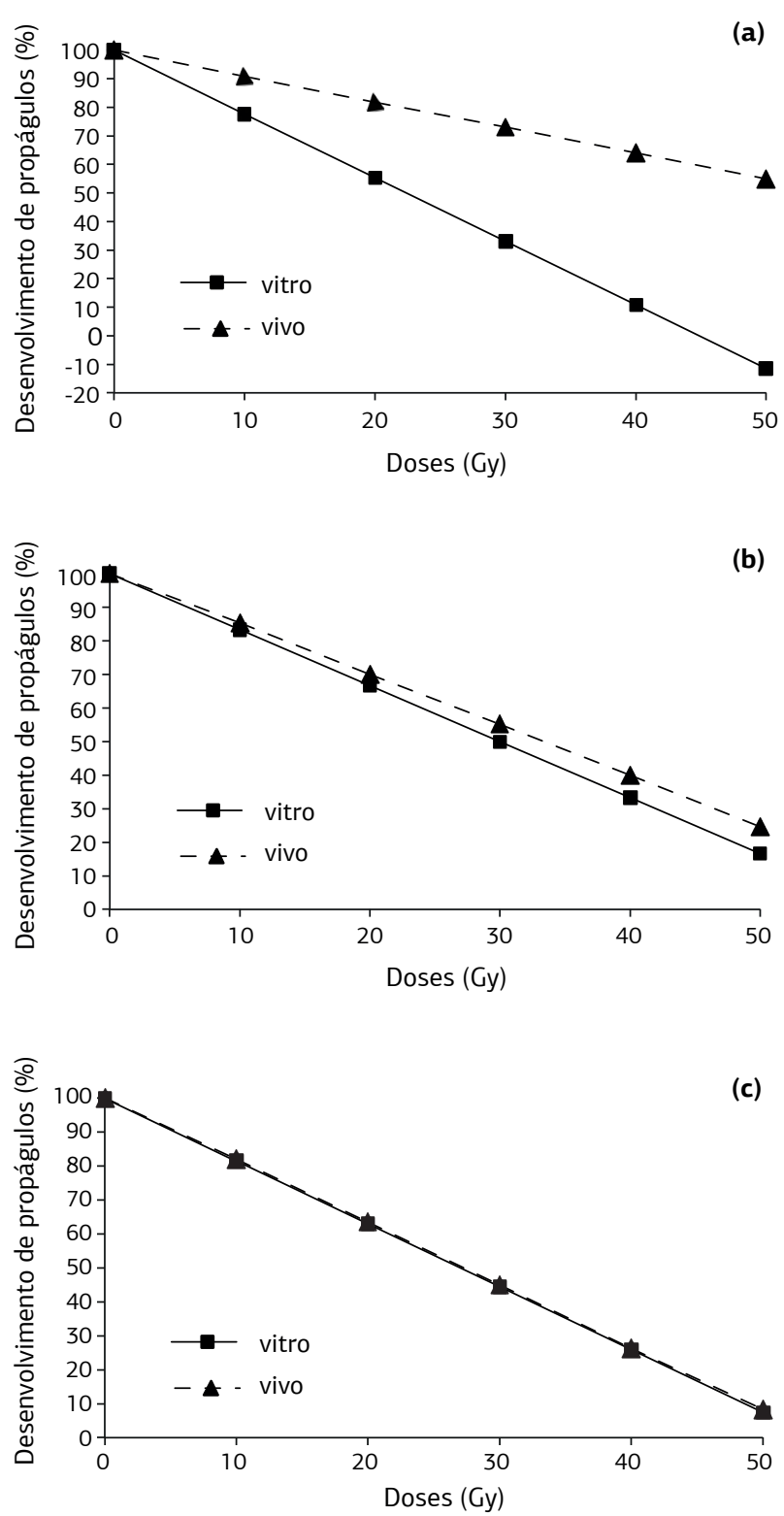

Figura 1. Equaçóes de regressão linear dos dados de desenvolvimento de propágulos in vivo (borbulhas) e in vitro (segmentos de epicótilo) de três variedades de citros. Os dados foram ajustados para a mesma escala, com valores relativos em relaçáo ao maior valor considerados como 100\%. (a) Tangerina 'Fremont'; (b) Tangerina 'Thomas' e (c) Tangor 'Murcott'. para segmentos de epicótilo e borbulhas respectivamente (Figura 1c).

As principais conclusóes observadas foram as de que as diversas doses de radiaçáo aplicadas nas borbulhas causaram reduçôes crescentes na altura das brotaçôes desenvolvidas, mas sem causar diferenças entre três variedades. No entanto, quando utilizada em propágulos in vitro (segmentos de epicótilo) a radiação causou reduçáo significativa somente no tangor 'Murcott' e no limão 'Cravo'. De maneira geral, a radiossensibilidade foi muito semelhante entre espécies e variedades quando utilizado o mesmo tipo de propágulo. O mesmo foi observado quando os dois tipos de propágulos (segmentos de epicótilo e borbulhas) foram comparados para a mesma espécie. A excessão foi observada na tangerina 'Fremont' com maior sensibilidade nos segmentos de epicótilo do que nas borbulhas.

\section{REFERÊNCIAS}

DAVIES, F.; ALBRIGO, L. Citrus. Wallingford: CAB International, 1994. 254p.

GULSEN, O.; UZUN, A.; PALA, H.; CANIHOS, E.; KAFA, G. Development of seedless and Mal Secco tolerant mutant lemons through budwood irradiation. Scientia Horticulturae, v.112, p.184-190, 2007.

HEARN, J. Development of seedless orange and grapefruit varieties through seed irradiation. Journal of the American Society for Horticultural Science, v.109, p.270-273, 1984.

KOCHBA, J.; SPIEGEL-ROY, P. The use of Citrus tissue culture for mutation breeding: Effects of plant growth substances and gamma irradiation of embryogenesis. In: Improvement of Vegetatively Propagated Crops and Tree Crops Through Induced Mutations. Wageningen: IAEA, 1976. pp.83-92.

KOCHBA, J.; SPIEGEL-ROY, P. Cell and tissue culture for breeding and developmental studies of citrus. HortScience, v.12, p.110-114, 1977.

MALIK, M.N.; SCORA, W.W.; SOOST, R.K. Studies on the origin of the lemon. Hilgardia, v.42, p.361-382, 1974.

POMPEU JUNIOR, J. Porta-enxertos In: MATTOS JUNIOR, D.; DE NEGRI, J.D.; PIO, R.M.; POMPEU JUNIOR, J. (Ed.). Citros. Campinas, 2005. p.61-104.

SHANCHUN, C.; FENG, G.; JINREN, Z. Studies on the seedless character of Citrus induced by irradiation. Mutation Breeding Newsletter, v.37, p.8-9, 1991.

SPIEGEL-ROY, P. On the chimeral nature of the Shamouti orange. Euphytica, v.28, p.361-365, 1979.

SPIEGEL-ROY, P.; PADOVA, R. Radiossensivity of Shamouti orange (Citrus sinensis) seeds and buds. Radiation Botany, v.13, p.105-110, 1973. 
SPIEGEL-ROY, P.; KOCHBA, J. Stimulation of differentiation in orange (Citrus sinensis) ovullar callus in relation to irradiation of the media. Radiation Botany, v.13, p.97-103, 1973.

SPIEGEL-ROY, P.; KOCHBA, J., Mutation breeding in citrus. In: Induced Mutations in Vegetative-Propagated Plants. IAEA, 1975. p.91-105.

SPIEGEL-ROY, P.; VARDI, A.; ELHANATI, A. Seedless induced mutant in highly seeded lemon (Citrus limon). Mutation Breeding Newsletter, v.36, p.11, 1990.
TULMANN NETO, A.; ANDO, A.; MENDES, B.M.J. Indução e uso de mutações in vitro. In: TORRES, A.C.; CALDAS, L.S. (Ed.). Técnicas e Aplicaçóes da Cultura de Tecidos de Plantas. Brasília, 1990. p.341-378.

TULMANN NETO, A.; ANDO, A.; MENDES, B.M.J. Progressos na indução e uso de mutaçóes in vitro. In: TORRES, A.C.; CALDAS, L.S.; BUSO, J.A. (Org.). Cultura de Tecidos e Transformação Genética de Plantas. Brasília: EMBRAPA, 1998, v. 1, p.459-509. 